\title{
A Comprehensive Evaluation of Learning Objects-Enriched Instructional Environments in Science Classes
}

\author{
Yalin Kilic Turel \& Mehmet Gurol \\ Firat University, Turkey
}

\begin{abstract}
Although there are many studies focusing on usefulness of learning objects, only a few studies investigated possible effects of learning objects at the middle-school level. Thus, the purpose of this study is to examine the effects of learning objects-enriched instructional settings on 7th grade students' achievements, retentions, attitudes, and motivations in the science class as well as their perceptions towards the course. Learning objects regarding the unit of structure and features of matter were placed into the Learning Management System, Moodle, which was accessible by science teachers of the participants. Almost all subjects pointed out that they preferred such teaching method hereafter because of its positive effects on their learning and remembering. The interactive and challenging learning objects, particularly the ones containing games, simulations, and questions, were identified as more beneficial by both teachers and students.
\end{abstract}

Keywords: Attitudes; Learning objects; Learning objects-enriched instruction; Motivation; Retention

\section{Introduction}

Recently, technology integration into instructional settings has become one of the most popular topics. Electronic instructional materials have played an important role to facilitate and improve the technology integration process. However, unstandardized structures of instructional materials have become the main impediment for their effective uses (Mclean and lannella, 2002). To this end, the concept of Learning Objects (LOs), also called as reusable learning objects, has emerged and been adopted as an effective approach for the design and utilization of instructional materials. Learning objects (LOs) refer to the digital resources that can be saved in databases systematically and used for instructional purposes. They have become a leading tool in the area of instructional technology owing to their viable features such as reusability, accessibility, and interoperability. Particularly, over the last 10 years, numerous studies have been conducted regarding LOs and their various utilizations. Although the main principle of LOs is to create instructional items that can be re-used multiple times in different instructional contexts (Salas and Ellis, 2006), most of LOs research have been conducted in higher education (Haughey and Muirhead, 2005; Kay and Knaack, 2007a,2009). Furthermore, studies related to LOs are generally involved in finding out the effectiveness of one learning object (LO) instead of discovering the various implications of LOs in real learning settings as contributory technology for learning (Kay and Knaack, 2007a). Consequently, we aimed to determine positive and negative dimensions of using LOs in middle school science classes in terms of students' perspectives and students' learning. 


\section{Summary of Learning Objects}

With the increasing numbers of traditional electronic instructional materials, instructors and researchers have to design and store these materials in a systematic way, known as Learning Object (LO) approach. Wiley (2002) suggested that LO is 'any digital resource that can be reused to support learning' in his work. Rehak and Mason (2003), on the other hand, preferred to define LO as 'a digitalized entity which can be used, reused or referenced during technology supported learning'. These digital assets can be stored and retrieved easily according to specific standards and used as time-independent and context-independent. LOs can also be in different file formats such as picture, audio, movie, animation, or web page (Wiley, 2002). Students and teachers can use LOs in traditional and on-line educational contexts in order to contribute to instruction for several purposes (Jones, 2004; Churchill, 2007). These materials should be stored systematically into a database called a repository. In order to retrieve the materials from the repository, each object should be tagged with Metadata defined as data about data. Metadata contains information about the main aim of the LO, its target group(s) and designer, date created and modified, size, type, and usage. Both tagging and storing processes have particular standards such as IEEE Learning Objects Metadata (LOM) Standard. Merlot, CAREO and Wisc-Online are some of the well-known repositories in the world. In Turkey, AtaNesA is the first repository, which offers more than 9000 LOs in different formats in Turkish, founded in Atatürk University in Turkey (ATANESA, 2011).

\section{Related Research}

As a popular research topic, LOs were investigated in terms of various variables and dimensions including success, performance, attention, learning, motivation. There are several studies conducted so as to ascertain the solid success and effectiveness of LOs. In one of the previous studies, 351 video-based LOs in sign language were designed and implemented successfully to deaf people in USA (Lehman and Conceicao, 2007). In another study, 9-yearold-students used LOs independently within a 15-20 hour period during a unit on fractions (Kong and Kwok, 2005). Students who used LOs outperformed students who learned from different sources other than LOs (Kong and Kwok, 2005). Anglin, Vaez, and Cunningham (2004) suggested that course content enriched by animations could support learning successfully.

Similarly, Jaakkola and Nurmi (2004) extended the LOs and traditional material (non-digital) comparison research by separating the college students into three groups based on their material usage: (1) only LOs, (2) only traditional materials, and (3) combination of traditional materials and LOs. Researchers found that the third group was superior to the other groups while the first group of participants, who used only LOs, performed better than the second group participants, who used only traditional materials (Jaakkola and Nurmi, 2004). Another study used flash animations and html-based LOs in order to investigate the effects of information transfer and retention skills of learners, and substantial development for these variables were noticed (Bradley and Boyle, 2004). By supporting those findings, Mayer and Moreno (2002 as cited in Namuth et al., 2005) reveal that animations, designed in different ways, both may trigger learning and are vital for teaching abstract and scientific concepts more effectively. 
In Turkey, Akpinar and Simsek (2007) have proved that LOs, designed by both teachers and professional instructional designers for mathematics, have a positive impact on students' learning. Similarly, in Estonia, Väljataga (2005) suggested that LOs facilitated learning and provided an interactive learning for students when they were used as a part of problem-based activities.

On the other hand, Donovan and Nakhleh (2007) designed web-based learning object tutorials for a chemistry course and examined the differences between students who used those tutorials and students who did not. They realized that although there was not any statistically significant difference between both groups: the conceptual understanding of students who used web-based tutorials which support traditional learning were improved better. With the purpose of measuring the effectiveness of LOs in science classes, Kay and Knaack (2009) conducted a study among 503 students and 15 instructors in 27 science classrooms by using five reliable and valid instruments. They concluded that science-based LOs were helpful tools in secondary schools while both teachers and students were satisfied with the learning and engagement value of LOs (Kay and Knaack, 2009).

Although we could not find any studies, which specifically examine retention, there are several studies that demonstrate the positive effects of electronic instructional materials on retention (Doymus et al., 2006; Gungormus, 2007; Gurbuz, 2007).

There are few studies that concentrated on perceptions and attitudes of learners towards LOs (Bratina, Hayes, and Blumsack, 2002; Kay and Knaack, 2007b, 2008b, 2009; Salas and Ellis, 2006). A study conducted in higher education has exerted that the satisfaction levels of students who had courses enriched by LOs during three semesters have increased (Salas and Ellis, 2006). In another study, students working with electronic instructional materials (ematerials) in general found them motivating (Ayersman, 1996). Considering different types of LOs, students mostly prefer the ones which are motivating, visual, and include hands-on activities (Kay and Knaack, 2007b). To some extent, positive motivational effects of LOs as ematerials can be explained with their new and interesting nature.

On the other hand, LOs may negatively affect some students, for example, who have computer anxiety (Akerling and Trevitt, 1999 as cited in Olkinuora et al., 2004). Bratina et al. (2002), who designed podcast LOs, suggested that it is possible to draw and maintain student's attention using LOs enriched by popular music, colorful pages and qualified animations.

Kay and Knaack (2008b) assessed two other variables, attitude and performance. They found that the higher classes have more positive attitudes towards LOs and also attitudes in science classes are significantly higher than mathematics classes. They also asserted that all of the students used LOs and their teachers reacted positively towards LOs.

In contrast to positive outcomes of LOs, researchers including Krämer (2005), Parrish (2004), and Leinonen (2005) have highlighted several concerns regarding misuse and unclear contributions of LOs in terms of instructional purpose. Therefore, more research should be conducted to address effective use and implications of LOs in practical settings. 


\section{Science Education in Turkey}

In Turkey, there has been one of the most extensive educational reforms of the last 60 years in 2005 (Kaya, 2009). In this context, curricula of science in elementary education have been redesigned by considering various pedagogical approaches such as constructivism, active learning; and models including the spiral curriculum model with the increased integration of technology by Turkish Ministry of National Education (MoNE). Moreover, MoNE has changed the name of these classes from "Science" to "Science and Technology" in elementary schools (MoNE, 2011). According to the new curricula, MoNE encourages teachers to use various types of instructional materials such as graphics, simulations, and audio so as to make teaching science concepts and processes easier and more effective (MoNE, 2011). MoNE also supports the reforming teaching methods instead of merely the 'chalk and talk' method, which is regarded as the dominant method in educational programs in developing countries (Kaya, 2009). Another essential point is that the spiral curriculum model was adopted by MoNE as the new curricula. According to this model, MoNE has distributed the course content to Grade 4 through Grade 8 in a complementary and progressive way by organizing the content based on the principles of simple-to-complex and easy-to-hard (Ceken, 2010).

Utilizations of learning objects as supportive instructional tools in science and technology education have the potential to facilitate the main objectives of the new curriculum and make substantial contribution to its successful implementation in several ways. For instance, the unit of 'Force and Motion' has been embedded into the programmes, range from Grade 4 to Grade 8 , by focusing on a particular dimension of the unit for each grade such as moving, pulling, and pushing objects in Grade 4; magnetism and friction force in Grade 5; work and energy in Grade 7; and buoyancy force and pressure in Grade 8 (MoNE, 2011). Owing to the reusability of learning objects, teachers can use well-designed reusable LOs in same units of Science and Technology courses for all grades (4-8).

However, there is a lack of comprehensive research related to LOs' use in the Turkish educational system. Therefore, taking motivation, commonly accepted as critical to learning, into consideration as a dependent variable may be regarded as a distinguished part of this study as well. Two essential factors including attitude and motivation were considered together to reach deeper and stronger findings in this research. Traditionally, educators have preferred to use both open source platforms and freely accessible and usable LOs to prove to teachers that they can execute the same system into their courses easily. This study is quite crucial in presenting a solution to the problems mentioned above.

\section{Problem}

Based on the literature review, it should be noted that there are various problems with the learning objects research. Although several dimensions of LO including design, development, re-usability, and standards have been examined especially for the last ten years, researchers have not fully benefited from LO's potential in a practical scope of applications (Kay and Knaack, 2005, 2008b; Sosteric and Hesemeier, 2002). Some studies stress that there is a lack of studies that prove the success of LOs explicitly (Kay and Knaack, 2005; Leinonen, 2005; Nurmi and Jaakkola, 2005; Sosteric and Hesemeier, 2002). Additionally, since studies were conducted mostly in higher education settings, the effectiveness and success issues for primary and 
secondary schools were not adequately taken into consideration (Haughey and Muirhead, 2005; Kay and Knaack, 2008a, 2009). Another issue that this study attempts to address is the paucity of research focusing on the effectiveness of LOs in science education using Turkey as a model.

After considerable examination of those problems regarding learning objects implementation and evaluation studies, we attempt to fill the gap by seeking answers to the following research questions:

- Do learning objects-enriched instructional settings have significant impact on students' attitudes?

- Do learning objects-enriched instructional settings have significant impact on students' motivation?

- Do learning objects-enriched instructional settings have significant impact on students' achievement?

- Do learning objects-enriched instructional settings have significant impact on students' retentions?

- What were students' and teachers' perceptions towards learning objects-enriched instructional settings?

\section{Methodology}

\section{Participants}

The first aim of this study is to determine the effects of learning objects on 7th grade students' motivation, attitude, and achievements when they are taught the unit of the structure and features of matter within a learning environment enriched with learning objects. Therefore, 78 students ( 51 female, 27 male) from two government schools in the Eastern Anatolia region of Turkey, participated in this study. Detailed information are presented in Table 1 below.

\section{Design}

Since this study aims to investigate the participating students' and their teachers' perceptions of such a learning environment, quantitative and qualitative methods were used together, which is called mix method in the literature (Yıldırım and Simsek, 2005). This approach enables us to establish the multi-dimensional picture of results that is closest to the real one and also empowers validity and credibility of research conclusions counteractively (Todd et al., 2004).

The data collection process of this study consists of an experimental method and Solomon four-group design. For all four groups of subjects, only two groups (one experimental group and one control group) were subjected to pre-tests while the others were administered both pre-tests and post-tests in Solomon design (Bonate, 2000). This model provides a higher level of internal validity as well as the external validity by decreasing the pre-test's effect on the post-test; therefore, it is one of the most desirable of all experimental designs (Bonate, 2000; Helmstadter, 1970). 
In this study, experimental groups represent the learners exposed to instructional environments enriched with learning objects while the control groups represent the students taught in a traditional way. Total numbers of students $(n=78)$ from two separate schools (School A and School B) participated in implementation. Two 7th grade classes in each of the schools, experiment groups (AE: School A-Experiment and BE: School B-Experiment) and control groups (AC: School A-Control and BC: School B-Control) were determined randomly based on the Solomon's model. All groups and subjects are presented below in Table 1.

Table 1. Main Statistics About Subjects

\begin{tabular}{ccccccccc}
\hline \multirow{2}{*}{ School } & \multirow{2}{*}{ Groups } & \multirow{2}{*}{ Tests } & \multirow{2}{*}{ Acronym } & \multicolumn{2}{c}{ Female } & \multicolumn{2}{c}{ Male } & Total \\
\cline { 5 - 8 } & & & $\boldsymbol{n}$ & $\%$ & $\boldsymbol{n}$ & $\%$ & $\boldsymbol{n}$ \\
\hline \multirow{2}{*}{ A } & Experiment & Post & AE & 13 & 65 & 7 & 35 & 20 \\
& Control & Post & AC & 15 & 75 & 5 & 25 & 20 \\
\multirow{2}{*}{ B } & Experiment & Pre+Post & BE & 11 & 57.9 & 8 & 42.1 & 19 \\
& Control & Pre+Post & BC & 12 & 63.2 & 7 & 36.8 & 19 \\
\hline & & & Total & 51 & 65.4 & 27 & 34.6 & 78 \\
\hline
\end{tabular}

As a qualitative research design, action research, which is defined as initiatives uncovering the actual knowledge regarding systems and their dynamics by covering a variety of approaches (Reason and Bradbury, 2008), was adopted. Sample groups were drawn from 7th grademiddle-school students as two experimental and two control groups. A range of criteria were used for sample selection. In terms of school selection, schools that had a projector, a computer, and Internet connection were selected. Also, in terms of teacher selection, teachers who had a personal computer and internet access were preferred. In addition to sample selection, another important part of this study was to complete selection of learning objects in order to develop an online platform for implementations, and to organize an orientation program for teachers before putting the project in action. Consistent with the aim and context of the study, 120 learning objects were pre-selected from 57 learning objects repositories by researchers and one science and technology teacher, aligned with the learning objectives of the determined course unit. Evaluations of 120 learning objects were done by two subjectmatter-experts (science teachers) and one instructional science expert (from the department of instructional sciences) based on the peer-review process (Bilgin and Geban, 2002).

In total, 98 learning objects in different formats including text/HTML (7), pictures (2), animations (39), videos (3), tutorials (10), simulations/games (16), and interactive questions (21) were chosen for this study. Most of the LOs were in Turkish except the ones including international symbols, pictures, and equations. During the selection process of the LOs for the implementation, we used a wide range of LO formats instead of using specific formats such as only animations and simulations.

On delivering these LOs, Moodle Platform, an open source learning management system that offers low cost, easy-to-use, Turkish language support, was considered as an interface for this study. Moodle also offers a variety of extensions and modules including forum, announcement, questionnaire, homework, and communication tools that both teachers and students can use handily. Thus, the Moodle package was installed in a special domain 
pertaining to this research (Figure 1). The weekly instruction option is preferred for the course main page so that teachers can display the appropriate course content for each week.

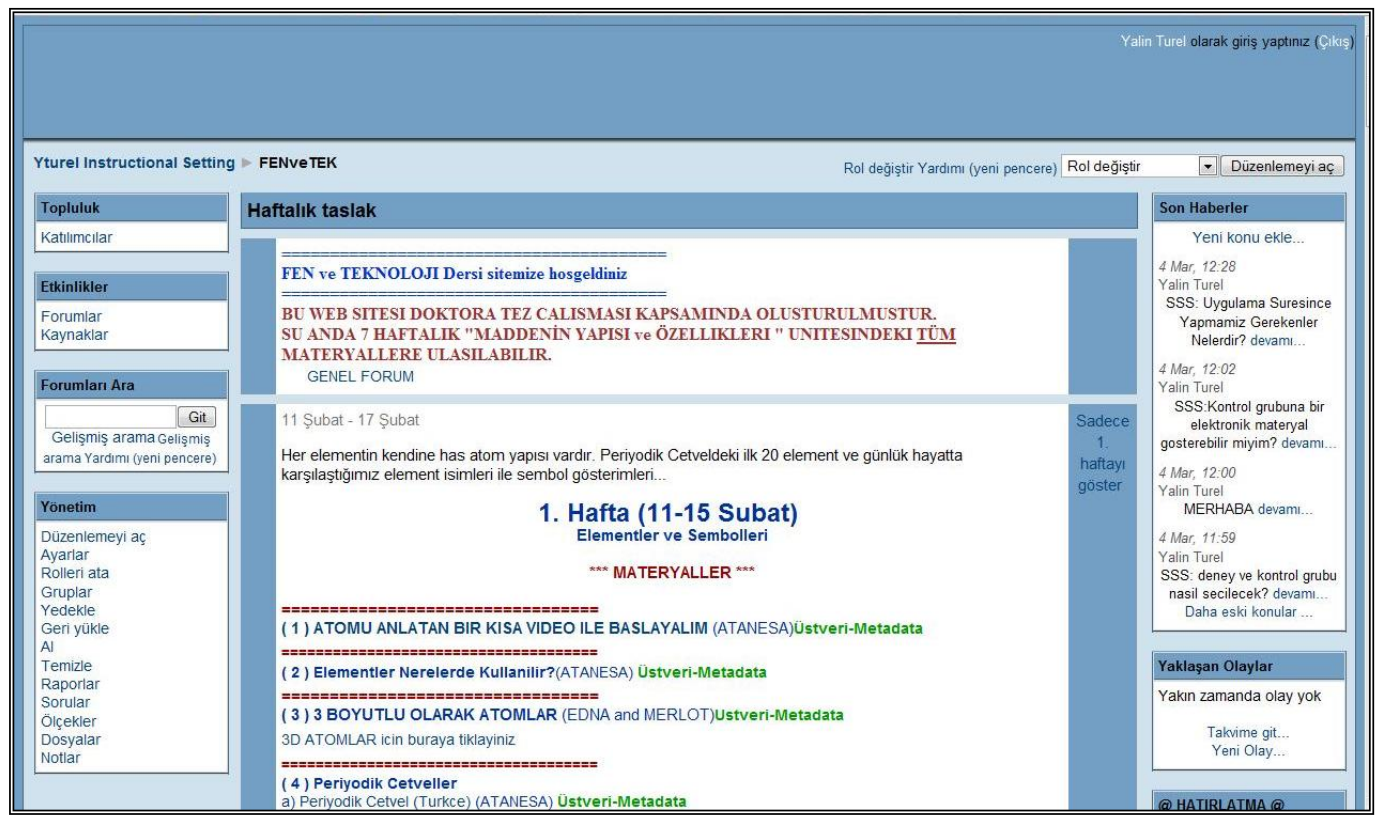

Figure 1. Screenshot of Moodle Platform

After this phase of study, the LOs and their descriptive Metadata were uploaded to the Moodle system. Meanwhile, teachers completed the teacher orientation program training them on how to use such systems, how to use learning objects, and recommended instructional strategies which support active and constructivist learning approaches.

\section{Instruments}

Meantime, attitude and motivation surveys, and achievement tests were conducted. For measuring students' motivation Keller's (1995) Course Interest Survey (CIS) was used to examine the motivation levels of students towards the science course taken. Keller (1995) developed this survey for evaluating a situational measure of motivation of students in particular classroom settings (Halat et al., 2008). CIS is comprised of 34 statements categorized into four dimensions: Attention, Relevance, Confidence, and Satisfaction. Originally reliability values of CIS were calculated by Cronbach's Alpha measure for each subscale as follows: Attention: 0.84, Relevance: 0.84, Confidence: 0.81, Satisfaction: 0.88, and, Total Scale: 0.95. Varank (2003) translated the original survey from English to Turkish and repeated the reliability and validity tests. He calculated the Cronbach's Alpha values as 0.55 for Attention, 0.59 for Relevance, 0.67 for Confidence, 0.59 for Satisfaction, and 0.83 for overall tests (Varank, 2003).

We also developed an attitude survey and an achievement test specifically for this study. Details regarding development processes and results of the pilot tests' analyses for attitude survey and achievement test are illustrated below. 
We designed the Attitude Survey based on reviewing similar studies which examined the attitudes of students towards any course. For the reliability and validity of the attitude survey, considering experts' opinions regarding each item, the pilot test was administered to 300 primary school students. As a result of the reliability and validity analyses of the 5-point Likerttype scale, a 16-item, one-factor scale was designed in order to measure middle school students' attitudes towards a science and technology course. According to the reliability tests, KMO (Kaiser-Meyer-Olkin Measure of Sampling Adequacy) value and Cronbach's Alpha value were calculated as 0.94 and 0.91 , respectively. Therefore, it can be noted that reliability of the survey is quite satisfactory.

In order to fully understand the effectiveness of such systems, it was necessary both to measure the achievement effects of the implementation and to examine the differences of success and retention levels between control and experiment groups. Therefore the achievement test was designed by researchers and science and technology teachers. For reliability and validity, the test was administered to 291 eighth grade students. Based on itemanalysis, several questions were deleted and finally the KR-20 reliability coefficient for the 31item test was calculated as 0.65 . The test was given as pre- and post-tests to students as it was shown in Table 1. Six weeks after post-tests, we re-administered the achievement test to all participants to measure their retention levels. The goal of the retention test is to determine the changes of the achievement scores of the students based on the differences between experimental and control groups.

For ascertaining the perceptions of both teachers and students towards learning objects supported instruction, qualitative data were collected through interviews and open-ended questions. During the 8 week-period of the implementation process, teachers and students filled out a weekly assessment form comprised of open-ended questions. Students' assessment forms contained three questions: "What did you like in your class most today?", "what did you not like today?", and "what did you learn today?" On the other hand, teachers' assessment forms were more comprehensive compared to the students'. Some of the questions from the teachers' form included:

- Were you satisfied with today's lessons or not? Why?

- What were the reactions of your students towards LOs?

- What differences did you recognize during your instruction today, in terms of students' performance and attitude based on their genders?

- Which LOs were more useful for your instruction?

- What are the difficulties or problems you have encountered while using LOs?

- What is your general opinion about today's lesson?

At the end of the study, students and teachers were interviewed in order to obtain their general perceptions towards implementation. The coding process was aligned with the Grounded Theory methodology (Glaser and Holton, 2004). The created codes and all other qualitative data sources were transferred to QSR NVivo 8.0 and Microsoft Word and then analyzed. 


\section{Findings and Discussions}

For the School B, BE and BC groups took pre-tests and post-tests for both motivation and attitude surveys, respectively. One-way-analysis of variance (ANOVA) was employed to test the relationship between pre-test and post-test results of School $B$. The test of significance was primarily performed at the probability level of $p<0.05$. According to the ANOVA test results, there were no significant differences between the groups regarding their answers to the attitude surveys $(F=1.106, p>0.05)$. Also, there are no statistically significant differences between experimental and control groups for both surveys (see Figure 2 and Figure 3 ). In addition to ANOVA tests, each item was compared with Wilcoxon Signed-Ranks test to ascertain whether there were any significant differences between pre-test and post-test responses of the groups at School B (BE and BC) for each item. We found significant differences in terms of two items in the attitude survey: I like Science and Technology ( $p=$ $0.025)$ and I would not have felt the absence of Science and Technology, if it did not exist (reversed item) $(p=0.028)$.
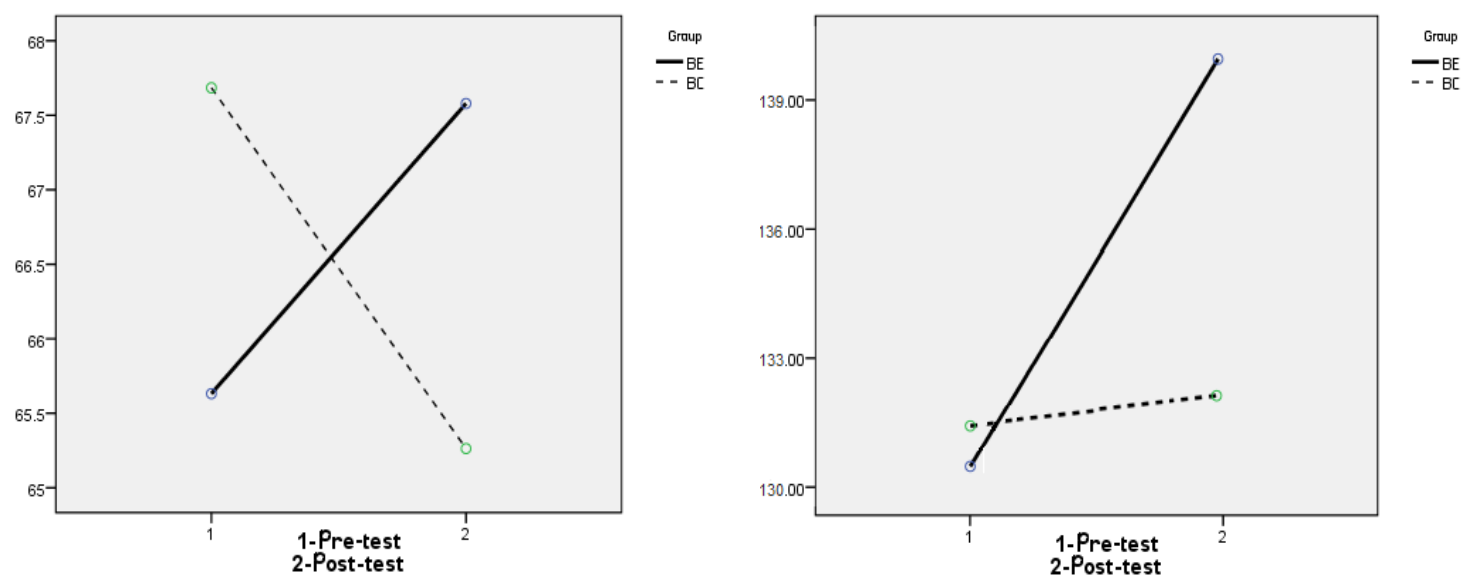

Figure 2. Differences in Attitudes of Students

Figure 3. Differences in Motivations of Students

On assessment of motivation measured by Keller's (1995) Course Interest Survey, there was no significant difference between pre-test and post-test scores based on ANOVA results. As seen in Figure 3, the experimental group shows a slight increase compared to the control group but it is not statistically significant. Wilcoxon Signed-Ranks test was employed again to test variation between pre-test and post-test scores for every single item. Based on the results of these tests, three items were seen as significant: The instructor knows how to make us feel enthusiastic about the subject matter of this course $(p=0.009)$, students in this class seem curious about the subject matter $(p=0.014)$, I get enough feedback to know how well I am doing $(p=0.017)$.

As for achievement effects of the LO enriched environments, the Two-Way ANOVA for mixed measures, Kruskal Wallis-H (KWH) non-parametric analysis of variance and Man Whitney-U (MWU) tests (since data were not normally distributed, we could not use parametric tests) 
were utilized to ascertain the status of and influence on the variables. In case of significant differences, the groups were pair-wise compared using Mann-Whitney analysis. According to achievement test scores of both groups who took pre-tests, post-tests and retention tests at School B, mean scores of the experiment group were slightly higher than the control group's (see Table 2).

Table 2. Achievement Tests' Mean Scores and Standard Deviations (Descriptive Statistics)

\begin{tabular}{cccccccccc}
\hline \multirow{2}{*}{ Groups } & \multicolumn{3}{c}{ Pre-tests } & \multicolumn{3}{c}{ Post-tests } & \multicolumn{3}{c}{ Retention Tests } \\
\cline { 2 - 11 } & $\boldsymbol{n}$ & $\boldsymbol{X}$ & $\boldsymbol{s} \boldsymbol{d}$ & $\boldsymbol{n}$ & $\boldsymbol{X}$ & $\boldsymbol{s} \boldsymbol{d}$ & $\boldsymbol{n}$ & $\boldsymbol{X}$ & $\boldsymbol{s} \boldsymbol{d}$ \\
\hline Experiment & 19 & 8.11 & 2.685 & 19 & 16.11 & 2.580 & 19 & 16.79 & 3.409 \\
Control & 19 & 7.58 & 2.694 & 19 & 13.26 & 4.617 & 19 & 13.58 & 4.273 \\
\hline
\end{tabular}

The Two-Way ANOVA for mixed measures used to compare the effects of the achievement indicated no significant difference on scores of pre- and post-tests for both groups. On the other hand, we observed a significant difference on scores of retention tests administered to all groups six weeks later than post-test based on Kruskal Wallis-H Test for Independent Samples (KWH) results (Table 3 ). In order to ascertain the significance across the four groups $(\mathrm{AE}, \mathrm{AC}, \mathrm{BE}$, and $\mathrm{BC})$, Mann Whitney $\mathrm{U}$ tests were performed (see Table 3 ).

Table 3. Comparison of Retention Tests Scores by means of KWH and MWU

\begin{tabular}{ccccccc}
\hline Groups & $\boldsymbol{n}$ & Mean Rank & $\boldsymbol{x}^{2}$ & $\boldsymbol{s d}$ & $\boldsymbol{p}$ & Significance \\
\hline AE & 20 & 53.32 & & & & AE-AC \\
AC & 20 & 37.08 & & & & BE-BC \\
BE & 19 & 40.61 & 14.132 & 3 & $0.003^{*}$ & AE-BC \\
BC & 19 & 26.39 & & & & AE-BE \\
Total (n) & 78 & & & & & \\
$* p<0.05$ & & & & &
\end{tabular}

The difference between mean scores of the retention tests of some groups were seen as significant $\left(x^{2}=14.132 ; s d=3 ; p<0.05\right)$. The performing tests of Mann-Whitney-U revealed statistically significant differences between the groups with: School A-Experiment (AE) and School A-Control (AC) groups $\left(U=124.000, n_{A E}=20, n_{A C}=20, p<0.039\right)$, School B Experiment (BE) and Control $(B C)$ groups $\left(U=104.000, n_{B E}=19, n_{B C}=19, p<0.025\right)$, School A-Experiment $(A E)$ and School B-Control (BC) groups $\left(U=110.500, n_{A E}=20, n_{B C}=19, p<0.025\right)$, and School A-Experiment (AE) and School B-Experiment (BE) groups $\left(U=69.000, n_{A E}=20, n_{B E}=19, p<\right.$ 0.001 ). Although there is no significant difference between post-test scores of $A E$ and $A C$, it is striking that a significant difference was observed for the retention test results of AE and AC. Mann-Whitney $U$ analyses comparing the groups pair-wise showed that the retention scores of experiment groups were significantly higher than control groups. Therefore, it can be concluded that learning objects enriched instructional settings have positive effects on students' information retention.

Qualitative data taken from interviews, open-ended questions and weekly reports were analyzed in keeping with the principles of Grounded Theory. Based on this approach, we determined parent codes and child codes which indicate the perceptions of students and 
teachers (Strauss, 1987; Glaser and Holton, 2004). Each statement pertaining to parent or child codes has been entered to QSR Nvivo software. Then, the codes were classified based on the literature and researchers' agreements. Benefits of implementation were branched into three main codes in terms of settings and ergonomy, instruction, and interest, motivation, and attitude while disadvantages were divided into four subsections in terms of ergonomy and environmental problems, instructional problems, interest and motivational problems, and technical problems. The child and parent codes for both positive and negative classifications based on qualitative data extracted from students' opinions were shown in Table 4.

Table 4. Benefits and Challenges of Implementation Based on Students' Views

\begin{tabular}{|c|c|}
\hline $\begin{array}{l}\text { Parent and sub-parent } \\
\text { codes }\end{array}$ & Child codes \\
\hline \multicolumn{2}{|l|}{$\begin{array}{l}\text { Benefits and } \\
\text { advantages }\end{array}$} \\
\hline $\begin{array}{l}\text { in terms of physical } \\
\text { environment and } \\
\text { ergonomy }\end{array}$ & $\begin{array}{l}\text { No need to draw figures, shapes to the blackboard (retrieving from } \\
\text { computer directly) } \\
\text { Physical appropriateness of instructional environment }\end{array}$ \\
\hline $\begin{array}{l}\text { in terms of learning } \\
\text { and instruction }\end{array}$ & $\begin{array}{l}\text { Better understanding, active learning } \\
\text { Facilitating learning } \\
\text { Helpful/useful } \\
\text { Retention } \\
\text { Not-taking } \\
\text { Lecture visually and orally } \\
\text { Student-centred involvement } \\
\text { Advantages peculiar to teacher } \\
\text { Asking questions/solving problems } \\
\text { Audio presentations } \\
\text { Learning by seeing pictures } \\
\text { Instructional activities (electronic games, simulations, interactive } \\
\text { questions) } \\
\text { Fluent instruction (smooth transition between activities) }\end{array}$ \\
\hline $\begin{array}{l}\text { in terms of interest, } \\
\text { motivation, and } \\
\text { attitude }\end{array}$ & $\begin{array}{l}\text { Funny } \\
\text { Encouraging and motivating } \\
\text { Increasing the concentration level } \\
\text { Interesting }\end{array}$ \\
\hline \multicolumn{2}{|l|}{$\begin{array}{l}\text { Disadvantages, defects } \\
\text { and problems }\end{array}$} \\
\hline $\begin{array}{l}\text { in terms of technical } \\
\text { problems }\end{array}$ & $\begin{array}{l}\text { regarding projection } \\
\text { regarding computer } \\
\text { regarding internet connection } \\
\text { regarding learning object itself } \\
\text { Need for technical assistant for teacher } \\
\text { Insufficient preliminary preparation }\end{array}$ \\
\hline $\begin{array}{l}\text { in terms of interest } \\
\text { and motivation }\end{array}$ & $\begin{array}{l}\text { Boring } \\
\text { Disliking }\end{array}$ \\
\hline $\begin{array}{l}\text { in terms of physical } \\
\text { environment and } \\
\text { ergonomy }\end{array}$ & $\begin{array}{l}\text { Noise } \\
\text { Disordered sitting plan, } \\
\text { Inconvenient chair-desk structure } \\
\text { Illumination and lighting } \\
\text { Insufficient vision of display screen }\end{array}$ \\
\hline
\end{tabular}




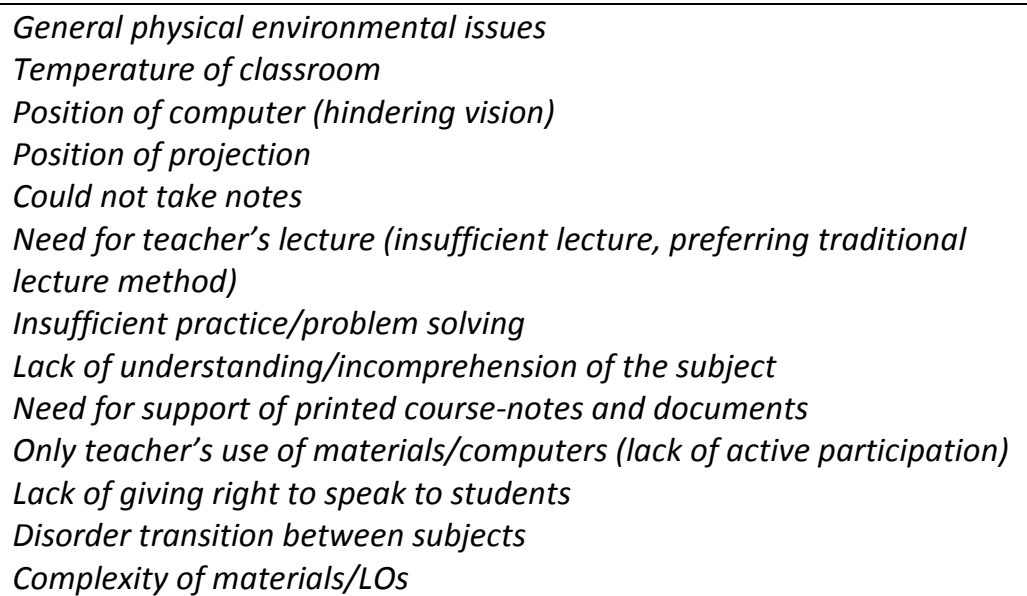

In order to exemplify the codes and their contexts, several examples from the collected data were presented in Table 5.

Table 5. Samples of Students' Statements

\begin{tabular}{|c|c|}
\hline Code & Statements \\
\hline Learning and instruction & $\begin{array}{l}\text { Students-A7: We learn better how electrons move and how their shapes are } \\
\text { as we have a lot of picture options. } \\
\text { Student-B4: We learn better because of materials' visual quality. } \\
\text { Student-A3: In my opinion, it was pretty nice implementation and should be } \\
\text { used in every course as well as science and technology. Students would be } \\
\text { more successful in this way. } \\
\text { Students-A6: It is a nice experience to see material with the lecture of } \\
\text { teacher. I suggest seeing material because to see the material provides } \\
\text { more permanent learning in my mind. }\end{array}$ \\
\hline $\begin{array}{l}\text { Interest, motivation and } \\
\text { attitude }\end{array}$ & $\begin{array}{l}\text { Student-A8: Games were drawing our attentions, because they were both } \\
\text { related with course content and they were funny. By playing games, we } \\
\text { could learn better and study lesson. } \\
\text { Student-A2: Because of being with image... Our teacher cannot paint such a } \\
\text { good picture. Even if she can, it will take much time. Teachers gave } \\
\text { examples on picture on the screen. }\end{array}$ \\
\hline $\begin{array}{l}\text { Negative statements (Did } \\
\text { you like this } \\
\text { implementation?) }\end{array}$ & $\begin{array}{l}\text { Student-B1: I did not like course progress. Because our friends make noise } \\
\text { too much and I could not understand anything from class. }\end{array}$ \\
\hline Teachers' lecture & $\begin{array}{l}\text { Student-B5: We cannot understand because our teacher cannot lecture } \\
\text { much... }\end{array}$ \\
\hline Need technical support & $\begin{array}{l}\text { Student-B9: If there were another person who knows about computer and } \\
\text { other technologies, he could use the computer and our teacher could teach } \\
\text { us and that would be great. }\end{array}$ \\
\hline Note-taking & $\begin{array}{l}\text { Student-B2: I did not like that my teacher did not make us take notes. } \\
\text { Because I can learn better by note-taking. }\end{array}$ \\
\hline
\end{tabular}

According to qualitative analysis, findings of implementation were summarized as advantages and disadvantages of the findings below. 


\section{Advantages}

- Using visual instructional materials enabled students to think they can learn the course content better and more permanently.

- Students generally found animations as a type of LO more beneficial.

- Instructional games and interactive questions were described as more interesting by students.

- Students emphasized that it is either difficult or impossible to draw figures and graphics demonstrated on computers in a traditional classroom setting.

- As a whole, supporting instructional settings with LOs was acknowledged as interesting and motivating by teachers and by the majority of students.

- It is possible to use a LO at various grades for the same or similar units in Science and Technology courses.

\section{Disadvantages}

- Although both schools' students highlighted 'noise' (simultaneous students' talk during material demonstration) as the most critical issue, School A had experienced this problem intensively.

- Several students stated that their teacher focused on the materials too much and, as a result, he/she wasn't able to lecture sufficiently. It may be concluded that students preferred traditional lecture from their teachers.

- Some students complained about not being able to either be involved in the implementation of LOs adequately or be given a chance to use LOs actively.

- Students commented on unsatisfactory physical circumstances of the classroom where implementations were done.

- Students agreed that materials comprised of either simple texts or complex content were ineffective.

- Teachers should be well prepared by testing all materials and technical hardware before using the materials.

- When teachers use learning objects not aligned with the active and student-centered approaches in their courses, this situation may negatively affect students' motivation and learning.

Conducting such research at two different schools with two teachers allowed us to obtain more extensive and richer findings about the research topic. In addition, when it was difficult to assess or make a comment concerning any part of quantitative data, related qualitative data helped us to interpret the situation. To exemplify, teachers' comments determined by their own observations were essential in supporting the results of surveys utilized to test the achievement, motivation, and attitude of the students as well as students' perceptions. When the teachers were asked about the reactions of their students towards the implementations, they commented that

Reactions of children are wonderful. Particularly in animations, interactive questions and matching games, children were highly interested and enthusiastic (Teacher-A). 
Students, especially boys, who have difficulty focusing on course content lost attention easily. They are better at the content containing videos, matching games, other games and questions. But generally girls are more active in my class (Teacher-B).

From these comments, it can be stated that especially interactive LOs were more challenging and motivating for students as Kay and Knaack (2007b) suggested. Teachers stressed that though it was often hard to hold students' attention, using LOs moderately could help students maintain focus on the course content. On the other hand, teachers declared they can freely use the same LO either without the need for modification or with a basic modification for future years and for various grades.

According to the comments of both teachers and students, it is obvious that LO-enriched settings provided more useful, productive, and permanent learning. All these positive comments also verified the results of the attitude, motivation, achievement, and particularly retention test scores of the students. To exemplify, most of the students in the experimental groups affirmed the positive effects of LOs on retention. Both teachers also emphasized that LOs facilitated learning and enabled students to retain information more permanently as it is supported by the higher retention test scores of the experimental groups. This finding parallels the findings of several studies including Bradley and Boyle (2004), Doymus et al. (2006), and Gungormus (2007).

In general, results of qualitative and quantitative data analysis reveal that LOs are satisfying, motivating, and attractive for learning as suggested by similar research (Akpinar and Simsek, 2007; Ayersman, 1996; Kay and Knaack, 2007b; Salas and Ellis, 2006; Valjataga, 2004).

\section{Conclusions and Recommendations}

It can be concluded that learning objects enriched instructional settings have positive effects on students' retention test scores. Also, the retention test scores of $A E$ (School $A$, experimental group) were significantly different than other groups' retention test scores. Based on the students' perceptions, it can be noted that the School-A teacher adopted the student-centered approach and allowed his students to actively use learning objects. Additionally, instructional settings enriched with LOs had positive impacts on students in terms of their attitudes and motivations based on the qualitative data analyses. However, for both the motivation and attitude surveys, there were no significant differences between experimental and control groups. Moreover, qualitative data show that students and also teachers used affirmative statements in their reflections towards this implementation and expressed that they would be pleased to experience such a practice hereafter.

In contrast to the positive outcomes of LO use, certain issues regarding the obtained data require our attention. In order to provide an effective implementation, the optimization of physical circumstances such as light, sound system, seating, position of projection screen, ergonomics of chairs and tables, and angle of sight is crucial. In addition to the physical requirements, all technical troubles should be resolved before instruction begins.

There are several important points of this implementation in terms of teachers. In the context of technology integration, utilization of LOs in classroom settings can contribute to the success 
of students, teachers, and consequently, curriculum, and can facilitate instruction in several ways. For example, the main features of LOs such as reusability and durability can be very supportive in terms of the new spiral curriculum model, which is based on placing the course content into various grades progressively and has been implemented since 2005 by Ministry of National Education (MoNE) in Turkey (MoNE, 2011). In their courses, teachers participating in the study also had a chance to use an open source learning management system (LMS), Moodle, one of the most used mediating tools for technology integration. However, teachers need to be trained more with respect to integration of technology into classrooms as well as computer literacy and internet technologies. Before graduation, it is critical for pre-service teachers to be given sufficient information about using LOs and drawing LOs from repositories. They should be provided the opportunity to use computers making them more active in implementations without feeling any computer anxiety. It is necessary that teachers are served repositories which provide well-designed and functional LOs so that they can select them depending on their needs. Those repositories can be supported by ministries of national education or similar initiatives. This solution may increase the effectiveness of instruction in schools. Similarly a platform for taking feedback about content and for delivering LOs to a larger crowd of people might be established. If a LO is designed as an open source and with different language packets, its usage will become easier and pervasive.

For future research, examination of this implementation in different educational levels and grades may give exciting results. Researchers may perform this system for varied units of science and technology courses or even in other discipline areas including mathematics, history, and literature by examining other variables such as creativity and misconception, and comparing the results.

\section{Acknowledgement}

This manuscript is a substantial part of first author's (Yalin Kilic Turel) PhD dissertation along with his advisor, the second author, Mehmet Gurol at Firat University. The authors would like to express special thanks to Dr. John Keller from Florida State University for his valuable contribution related this research.

\section{References}

Akpinar, Y. \& Simsek, H. (2007). Should K-12 teachers develop learning objects? Evidence from the field with K-12 students. International Journal of Instructional Technology and Distance Learnin, 4(3), 31-44.

Anglin, G. J., Vaez, H., \& Cunningham, C. L. (2004). Visual representations in learning: The role of static and animated graphics. In D. H. Jonassen (Ed.), Handbook of Research on Educational Communications and Technology ( $2^{\text {nd }}$ Ed.). Mahwah, NJ: Lawrence Erlbaum.

ATANESA (2011). Atatürk University Learning Object Repository. Retrieved on 20 March 2011 from http://www.atanesa.net.

Ayersman, D. (1996). Reviewing the research on hypermedia-based learning. Journal of Research on Computing in Education, 28(4), 500-526. 
Bilgin, I. \& Geban, O. (2002). Ogrencilerin grup calismalarindaki performanslari ile kimyasal denge konusu basarilari arasindaki iliskinin incelenmesi. Paper presented at $5^{\text {th }}$ National Science and Mathematics Education Congress. Ankara.

Bonate, P. L. (2000). Analysis of pretest-posttest design. Boca Raton, FL: CRC Press.

Bradley C. \& Boyle T. (2004) The design, development, and use of multimedia learning objects. Journal of Educational Multimedia and Hypermedia. 13, 371-389.

Bratina, T. A., Hayes, D. \& Blumsack, S. L. (2002). Preparing teachers to use learning objects. The Technology Source. Retrieved on 20 May 2010 from http://technologysource.org/ article/preparing_teachers_to_use_learning_objects/

Churchill, D. (2007). Towards a useful classification of learning objects. Educational Technology Research and Development, 55(5), 479-497.

Ceken, R. (2010). Hydrological cycle through spiral curriculum model in science education: The United States versus Turkey. International Online Journal of Educational Sciences, 2(2), 579-599.

Donovan, W. \& Nakhleh, M. (2007). Student use of web-based tutorial materials and understanding of chemistry concepts. Journal of Computers in Mathematics and Science Teaching, 26(4), 291-327.

Doymus, K., Dasdemir, I., Aksoy, G., \& Simsek, U. (2006). Fen derslerinin ogretilmesinde animasyonlarin etkisi. Paper presented at the $7^{\text {th }}$ National Science and Mathematics Education Congress, Ankara.

Glaser, B. G. \& Holton, J. (2004). Remodeling grounded theory. Forum Qualitative Sozialforschung / Forum: Qualitative Social Research, 5(2), Art. 4. Retrieved on 12 January 2011 from http://nbn-resolving.de/urn:nbn:de:0114-fqs040245.

Gungormus, G. (2007). The effect of games used in web based education on success and permanency (Unpublished master thesis). Ankara: Gazi University.

Gürbüz, R. (2007). Students' and their teachers' opinions about the instruction based on the materials on probability subject. Kastamonu Education Journal, 15(1), 259-270.

Halat, E., Jakubowski, E., \& Aydin, N. (2008). Reform-based curriculum and motivation in geometry. Eurasia Journal of Mathematics, Science and Technology Education, 4(3), 285292.

Haughey, M. \& Muirhead, B.(2005). Evaluating learning objects for schools. The e-Journal of Instructional Science and Technology (e-JIST), 8(1).

Helmstadter, G. C. (1970). Research concepts in human behavior: Education, psychology, sociology. New York: Appleton-Century-Crofts.

Jaakkola, T. \& Nurmi, S. (2004). Academic impact of learning objects: The case of electric circuits. Paper presented at the BERA (British Educational Research Association) 2004 Conference, Manchester, UK.

Jones R. (2004). Designing adaptable learning resources with learning object patterns. Journal of Digital Information, 6(1). 
Kay, R. H. \& Knaack, L. (2005). Developing learning objects for secondary school students: A multi-component model. Interdisciplinary Journal of Knowledge and Learning Objects, 1, 229-254.

Kay, R. H. \& Knaack, L. (2007a). A systematic evaluation of learning objects for secondary school students. Journal of Educational Technology Systems, 35(4), 411-448.

Kay, R. H. \& Knaack, L. (2007b). Evaluating the use of learning objects for secondary school science. Journal of Computers in Mathematics and Science Teaching, 26(4), 261-289.

Kay, R. H. \& Knaack, L. (2008a). An examination of the impact of learning objects in secondary school. Computer Assisted Learning, 24(6), 447-461.

Kay, R. H. \& Knaack, L. (2008b). A formative analysis of individual differences in the effectiveness of learning objects in secondary school. Computers and Education, 51(3), 1304-1320.

Kay, R. H. \& Knaack L. (2009) Assessing learning, quality and engagement in learning objects: The learning object evaluation scale for students (LOES-S). Educational Technology Research and Development, 57, 147-168.

Kaya, O. N. (2009). The nature of relationships among the components of pedagogical content knowledge of pre-service science teachers: 'Ozone layer depletion' as an example. International Journal of Science Education, 31(7), 961-988.

Keller, J. M. (1995). Motivation by design. Tallahassee, FL: Florida State University, College of Education.

Kong, S. C. \& Kwok, L. F. (2005). A cognitive tool for teaching the addition/subtraction of common fractions: A model of affordances. Computers and Education, 45(2), 245-265.

Krämer, B. J. (2005). Reusable Learning Objects: Let's give it another trial. Fern Universität in Hagen, Forschungsberichte des Fachbereichs Elektrotechnik.

Lehman, R. M. \& Conceicao, S. C. O. (2007). American sign language learning objects for instruction: A higher education perspective. In P. Northrup (Ed.) Learning objects for instruction. Hershey, PA: IGI Global.

Leinonen T. (2005). Learning objects - Is the King naked? Retrieved on 19 March 2009 from http://flosse.dicole.org/?item=learning-objects-is-the-king-naked.

MacDonald, C.J., Stodel, E., Thompson, T.L., Muirhead, B., Hinton, C., Carson, B., \& Banit, E. (2005). Addressing the eLearning contradiction: A collaborative approach for developing a conceptual framework learning object. Interdisciplinary Journal of Knowledge and Learning Objects, 1, 181-196.

Mclean, N. \& R. Iannella (2002). Digital rights management (drm) in education: The need for standardization. Briefing paper, Australian IMS Centre. Retrieved on 4 April 2007 from http:// xml.coverpages.org/IMS-Briefing-DRM-200202.pdf.

Mayer, R. E. (2003). The promise of multimedia learning: Using the same instructional design methods across different media. Learning and Instruction, 13, 125-139.

MoNE (2011). New curriculum of science and technology education. Retrieved on 12 March 2011 from http://ttkb.meb.gov.tr/ogretmen/modules.php. 
Namuth, D., Fritz, S., King, J., \& Boren, A. (2005). Principles of sustainable learning object libraries. Interdisciplinary Journal of Knowledge and Learning Objects, 1, 181-196.

Nurmi, S. \& Jaakkola, T. (2005). Problems underlying the learning object approach. International Journal of Instructional Technology and Distance Learning. 1(11).

Olkinuora, E., Mikkilä-Erdmann, M. \& Nurmi, S. (2004). Evaluating the Pedagogical Value of Multimedia Learning Material: An Experimental Study in Primary School. In N. Seel \& S. Dijkstra (Eds.). Curriculum, plans, and processes in instructional design. International perspectives. Mahwah, NJ: Lawrence Erlbaum.

Parrish, P. E. (2004). The trouble with learning objects. Educational Technology Research and Development, 52(1), 49-67.

Reason, P. \& Bradbury, H. (2008). Handbook of action research: Participative inquiry and practice ( $\left.2^{\text {nd }} E d.\right)$. London: Sage.

Rehak, D. R. \& Mason, R. (2003) Keeping the learning in learning objects. In Littlejohn, A. (Ed.) Reusing online resources: A sustainable approach to e-learning (pp.20-34). London: Kogan Page.

Salas K. \& Ellis L. (2006). The development and implementation of learning objects in a higher education setting. Interdisciplinary Journal of Knowledge and Learning Objects, 2, 1-22.

Sosteric M. \& Hesemeier S. (2002). When is a learning object not an object: a first step towards a theory of learning objects. International Review of Research in Open and Distance Learning. 3, 1-16.

Strauss, A. (1987). Qualitative analysis for social scientists. New York: Cambridge University Press.

Todd, Z., Nerlich, B., McKeown, S. \& Clarke, D. D.(2004). Mixing methods in psychology: The integration of qualitative and quantitative methods in theory and practice. Psychology Press.

Varank, I. (2003). The effects of computer training on Turkish teachers' attitudes toward computers and the effects of computer-supported lessons on Turkish students' reported motivation to lessons (Unpublished doctoral dissertation). Florida State University, Florida.

Väljataga, T. (2005). Design and evaluation of problem-based learning objects for environmental education in Estonian secondary school. e-Learning in Higher Education: EUDORA Intensive programme ELHE during the summer school in Viljandi, Estonia, Linz, Austria: Trauner Verlag, (pp.214-231).

Wiley, D. (2002). Learning objects need instructional design theory. In E. Rossett (Ed.), The ASTD e-Learning Handbook. Columbus, OH: McGraw-Hill.

Yildirim, A. \& Simsek, H. (2005). Sosyal bilimlerde nitel arastırma yontemleri. Ankara: Seckin.

Correspondence: Yalin Kilic Turel, Assistant Professor, Department of Computer Education and Instructional Technologies, Faculty of Education, Firat University, Elazig, Turkey 